\title{
Research on the Scope of Deposit Number Limited Claim of Strain Patents and the Furnishing of Deposited Strain
}

\author{
Zhang Xiaodong \\ Law School, East China University of Science and Technology, Shanghai, China
}

Email address:

xdzhang@ecust.edu.cn

\section{To cite this article:}

Zhang Xiaodong. Research on the Scope of Deposit Number Limited Claim of Strain Patents and the Furnishing of Deposited Strain. International Journal of Law and Society. Vol. 4, No. 1, 2021, pp. 47-53. doi: 10.11648/j.ijls.20210401.16

Received: February 17, 2021; Accepted: March 3, 2021; Published: March 17, 2021

\begin{abstract}
Because of the active research on microorganisms, there is a large number of deposit number limited claims of microorganism strain patents; at the same time, the total amount of deposited strains has increased continually. However, the scope of protection of these patents is unclear, and there are many restrictions on obtaining the deposited strains. This paper begins with a Chinese case involving strain patent infringement, discusses the scope of deposit number limited claim of the strain and suggests that this kind of claim can be interpreted as "a strain that has the same specific characteristics as the strain deposited in qualified depository institution" to retain flexibility in judgment. Specifically, the full genomic sequence should first be considered as the compared subject unless it is unavailable, and random mutations in the sequence can be assessed under the doctrine of equivalents. As for the propagation, multiplication, and gene recombination of patent strains, 98/44/EC has established rules for treating derivatives from biological materials, which are worth applying in this area. If deposit number limited claim of strain could get a broad scope of protection, the furnishing of the deposited strain should be more convenient, and strict restrictions on furnishing the strain should be relaxed.
\end{abstract}

Keywords: Deposit Number Limited Claim, Strain, Interpretation of Claim, Furnishing of Deposited Strain

\section{Introduction}

In the late 19th century, microbiology was established. To date, microorganism strain inventions are prevalent, and the application of microorganisms has thrived in many areas, such as the food industry, medicine, environmental improvement, the biochemical industry, ecological agriculture, renewable energy, and mineral mining.

Depending on whether reverse engineering can be used to obtain strains, the products involved in strains could be divided into three main types.

The first type is products containing living strains or their mixtures, for example, yeast for food fermentation; yogurt; edible fungus or algae; probiotics that can adjust the balance of intestinal flora; live microorganism pesticides for killing insects, bacteria or weeds; and live microorganism fertilizers such as nitrogen-fixing bacterial fertilizers. From these final products, it is possible to obtain the strains through reverse engineering.

The second type is purification products produced by using strains as catalysts, including various small or macromolecular compounds such as ethanol, glycerol, organic acids, antibiotics, vitamins, steroid hormones, enzyme inhibitors, immunity regulators, and receptor antagonists; polymers such as $\gamma$-polyglutamic acid, polyhydroxy fatty acid esters, xanthan gum, curdlan, and monascus pigment; and protein substances such as enzymes, interferons, growth hormones, vaccines, and antimicrobial peptides. It is impossible to extract the strains from these final products by reverse engineering.

The third type is fermentation products, which are mainly in the food field, including soy sauce, vinegar, wine, etc. The strains needed in the manufacturing process cannot be extracted from the final product.

Strains are easy to cultivate and proliferate; therefore, from a commercial perspective, the owner of a new strain desires to keep the strain confidential, especially strains used for producing the second type of products above. However, strains are difficult to maintain as trade secrets because they can be easily stolen [1] and are sometimes obtained by reverse engineering. An early biotechnology trade secret case involving a strain [2] illustrated some difficulties in keeping 
the strain confidential. In this case, valuable strains were developed and owned by Lederle Laboratories and were used in the manufacture of pharmaceutical antibiotics and steroids. Although the drugs were patented, the strains and detailed manufacturing processes were kept confidential. Two Lederle employees, Sidney Fox and John Cancelarich, continually stole the strains' cultures and sold them to other persons, but the employer discovered their illegal behavior two years later. In addition, the protection of trade secrets faces great difficulties in the determination of ownership and the collection of evidence of infringement.

Patents provide an alternative way to protect new strains. Since the Chakrabarty case [3], it has not been controversial whether microorganism inventions can be patented. In the past forty years, a large number of patents related to microorganisms have been generated, which fall into three categories: strains, preparation methods, and applications of microorganisms. Among these, the most important invention is the strain. Among strain inventions, the deposit number limited claim has occupied a dominant position, especially in China.

For genetically engineered strains, the method of genetic modification can be repeated to obtain the same strains, so deposition need not be applied. However, for other microorganism inventions, if those skilled in the art cannot reproduce the strain according to the patent description, the new microorganism strain must be deposited in a qualified international depository institution to meet the full disclosure requirements of the Patent Law. In this situation, the deposit number limited claim arose. So far, based on the Budapest Treaty on the International Recognition of the Deposit of Microorganisms for the Purposes of Patent Procedure, there are 48 international depositary authorities in 26 countries, and 3 of them are in China.

Because of the abbreviation code of one of the 48 qualified depository institutions appears in a deposit number limited claim, we can search these strain patents by searching the abbreviation codes. The data base is www.incopat.com; the search condition is $(($ CLAIM $=(C B A$ OR NMI OR BCCM OR NBIMCC OR IDAC OR CCHRGM OR CCTCC OR CGMCC OR GDMCC OR CCM OR VTTCC OR CNCM OR DSMZ OR NCAIM OR MCC OR MTCC OR ABC OR DBVPG OR IZSLER OR IPOD OR NPMD OR MSCL OR CM-CNRG OR CBS OR IAFB OR PCM OR KACC OR KCCM OR KCLRF OR KCTC OR VKM OR VKPM OR CCY OR BEA OR CECT OR CCOS OR CCAP OR ECACC OR IMI OR NCIMB OR NCTC OR NCYC OR NIBSC OR ATCC OR NCMA OR NRRL OR CCMM OR NAIMCC)) AND $(\mathrm{IPC}=(\mathrm{C} 12 \mathrm{~N} 1$ OR $\mathrm{C} 12 \mathrm{~N} 7 \quad$ OR $\mathrm{C} 12 \mathrm{R} 1)))$ NOT $(\mathrm{IPC}=(\mathrm{C} 12 \mathrm{R} 1 / 91 \quad$ OR $\mathrm{C} 12 \mathrm{~N} 5 \quad$ OR $\mathrm{C} 12 \mathrm{~N} 15 / 02))) \quad$ AND $(\mathrm{AD}=[19740428$ to 20201231$])$; the search deadline is 20210125. As the search result, the number of patent applications of this kind has reached 23,483 in China, 7,521 in the United States, 5,463 in the World Intellectual Property Organization (WIPO), 4,688 in South Korea, and 2,385 in Japan.

Regarding the large number of deposit number limited strain patents, some related basic issues lack in-depth discussion, such as the scope of the claims and the relationship between strain patent protection and the availability of deposited strains. In March 2020, the Beijing Intellectual Property Court of China decided the first deposit number limited strain patent infringement case [4]. This paper will start with this case and discuss the above issues.

\section{Factual Background of Shanghai FINC v. Tianjin LSPY}

\subsection{The Patent-In-Suit: CN Patent No. $103503780 B$}

The Patent-In-Suit is directed to a new kind of edible fungus, named "Pure white hypsizigus marmoreus strain" (CN103503780B, filed on Jan. 25, 2013), owned by Shanghai FINC Biotech Inc. (FINC). The strain was obtained by crossing the parental TNN-11 and $\mathrm{H}-\mathrm{W}$ and then systematically breeding. It was deposited in the China Type Culture Collection with deposit number CCTCC NO: M2012378. In the specification of the patent, the strain was characterized by morphological features and molecular biological features, including ITS rDNA sequencing, random amplified polymorphic DNA (RAPD) analysis, sequence-characterized amplified region (SCAR) molecular markers, etc. However, the full genomic sequence of this strain was not disclosed.

The patent has only one claim:

"A pure white hypsizigus marmoreus strain Finc-W-247 with deposit number CCTCC NO: M2012378."

\subsection{Action for Patent Infringement}

Shanghai FINC alleged that Tianjin Lvshengpengyuan Agricultural Technology Development Co., Ltd. (LSPY) and HongbinHesheng Company produced and sold the patented products without permission, which constituted infringement. The Beijing Intellectual Property Court accepted the case on June 22, 2017, held a public hearing on December 26, 2019, and made the judgment on March 24, 2020.

After the deposit number limited claim of strain was interpreted as the strain itself, the court focused on determining whether the alleged product infringed on the strain itself protected by the claim. Because comparative experiments had to be conducted, it was necessary to entrust civil judicial authentication. However, the court found that there was no mature precedent to follow for this new case. In pretrial talks, the plaintiff, FINC, proposed that the gene-specific fragments of the strain should be used for identification and comparison, but the defendant, LSPY, argued that the full genomic sequence of the strain should be used. Finally, the court suggested that the judicial authentication institution choose a suitable method based only on their professional knowledge.

The judicial authenticators found that the edible fungus of this case had dual-cell nuclei and needed to be divided into mononuclear forms before genetic sequence testing. However, 
this subcore method is not a standard method certified by China Inspection Body and Laboratory Mandatory Approval (CMA) and China National Accreditation Service for Conformity Assessment (CNAS). Therefore, they abandoned the full genomic sequencing, detected the internal transcribed spacer (ITS) rDNA sequence and the specific 975bp DNA fragment of the two samples according to the method specified in Example 12 of the patent for comparison. Based on the description of this patent (CN103503780B), the specific 975bp DNA fragment is the sequence-characterized amplified region (SCAR) molecular marker of the strain Finc-W-247. SCAR molecular markers are derived from random amplified polymorphic DNA (RAPD) [5]. The basic principle is to convert the dominant markers into codominant markers to reduce the tediousness of RAPD by molecular cloning. SCAR analysis has been used for the genetic characterization of microorganisms.

The authentication opinion was that the two samples were the same strain for the following reasons: (1) these two samples' specific 975bp DNA fragments were the same; (2) the similarity between these two samples' ITS rDNA sequences and the ITS rDNA sequence of Hypsizigus marmoreus HMB1 (HM561968) was 99.9\%; and (3) according to the morphological comparison, the color, shape, arrangement and other morphological characteristics of the cap, gill and stalk were largely the same.

In the judgment, the defendant LSPY questioned the rationality of the authentication method, so the Beijing Intellectual Property Court made the following comments on this issue:

"Superficially speaking, it is the most accurate method to test and compare the full genomic sequence of the alleged infringing product and the strain sample deposited by the patent. However, because the genes of microorganisms may be mutated, even if they are the same microorganisms, their gene sequences may not be completely the same. For two microorganisms, how great a ratio of similarity between them is needed in order to regard them as the same microorganism? In fact, there is no consensus on genetic sequence comparisons of microorganisms, not only regarding the comparison of the similarity of the two genetic sequences but also regarding the gene interpretation and analysis after gene sequencing. Due to the complexity of the genomic structure and bias in the sequencing process, it is indeed difficult to determine whether two microorganisms are the same based on the ratio of similarity between them. Therefore, the full genomic sequence comparison is uncertain and is not sufficient to correctly determine whether the alleged infringing product is the same microorganism as that involved in the patent".

As a result, the Beijing Intellectual Property Court confirmed that the method adopted by the judicial authentication institution was reasonable and finally ordered the defendants to cease infringement. The defendant, LSPY, compensated the plaintiff, FINC, 1 million Yuan for economic losses and more than 80,000 Yuan for reasonable expenditures to stop this infringement.

\section{The Scope of the Deposit Number Limited Claim of Strain Patent}

A new strain may be a wild-type strain purified from nature, a mutagenic strain screened after artificial conventional mutagenesis, or a genetically engineered strain produced through genetic engineering. For genetically engineered strains, the claim is generally clear with some detailed technical features; for example, Claim 1 of CN1981029B is "A genetically altered yeast strain that autonomously produces cholesterol from a single carbon source, characterized by expressing 7-dehydrocholesterol reductase and $3 \beta$-hydroxysterol $\Delta 24$-reductase."

However, the deposit number limited claim of strain patent is not so clear. The deposit number in the claim of a strain can be divided into two parts: one is the abbreviation code of the depository institution, and the other is the serial number assigned by the depository institution. For any claim, the scope is determined by the sum of all the technical features of the claim. In court proceedings, each technical feature must be checked individually. In this sense, can the depository abbreviation code and serial number be regarded as two technical features? Clearly, the answer is no. Even if the microorganism involved in the accused infringement is not furnished from the depository, there may still be infringement. In fact, deposition of the strain constitutes only a kind of evidence that can be provided by a third party when necessary.

In the case above, the deposit number limited strain claim was interpreted to the strain itself deposited in the qualified depository institution, but interpreting the strain itself was still a problem because specific technical features needed to be compared when determining patent infringement. Based on the methods adopted by the judicial authentication institution, the court finally interpreted the deposit number limited claim of the strain as its specific molecular markers, including SCAR markers and ITS rDNA sequences, and its morphological characteristics. However, this interpretation is not comprehensive. In this case, the SCAR molecular marker is just a distinguishing feature developed by the patentee in the process of distinguishing the patented strain from other selected contrast strains. In fact, a successful SCAR molecular marker must be tested for specificity against any other available microorganisms; otherwise it may not be able to prove the strain's uniqueness. In other words, it can be overturned. In a related patent invalidation case [6], the person requesting invalidation provided an evidence that the SCAR molecular marker 975bp DNA sequence of the strain Finc-W-247 can be obtained by the same method from another strain, ACCC 51532, deposited before the filing date, although this evidence had not been confirmed due to the lack of original documents. Clearly, there are some uncertainties in SCAR molecular markers. Research has also shown that the ITS rDNA sequence is usually used in phylogenetic studies in fungi and is not suitable for markers of species orpopulations within agenus [7]. In July 2018, the full genomic sequence of a kind of hypsizygus marmoreus (basidiomycetes) was sequenced [8], so there are no obvious obstacles to the subcore 
sequencing method.

It seems that interpreting the deposit number limited claim of a strain as its full genomic sequence is more appropriate. In fact, there are also patents that use genomic sequences to express their claims; for example, Claim 1 of $\mathrm{CN} 100558896 \mathrm{C}$ is "A long-bifidobacterium strain, its genomic and plasmid sequences are SEQ ID. NO. 1 and SEQ ID. NO. 2, respectively." However, we should note that not all strains can be tested to obtain a full genomic sequence because of difficulties such as $\mathrm{G}+\mathrm{C}$ content that is too low or too high or that contains many repetitive sequences [9]. Even if the full genomic sequence of the strain can be tested, because a small number of random mutations will be generated during the passage of strains, it is unfair to the patentee to divide the full gene sequence into single nucleic acid and strictly compare them one by one and judge only by literal infringement.

From the perspective of the balance of interests of the patentee and the public, the patents of microorganisms should be given a relatively flexible scope of protection that matches their contribution to society in order to encourage the innovation and disclosure of new strains. At the same time, it is necessary for the deposited strain to be easily available for subsequent research. The author's point of view is that the deposit number limited claim of strain could be interpreted as "a strain that has the same specific characteristics as the strain deposited in qualified depository institution," which preserves flexibility for judgment. Considering developments in gene technology, what is considered a "specific characteristic" depends on the individual case. When full genomic sequences can be tested, the sequences can be compared. Taking into account random mutations in the process of reproduction, it is not appropriate to treat the bases of the genomic sequence as separate features for strictly one-to-one comparisons. The case should be considered both literal infringement and infringement under the doctrine of equivalents. If the mutation can be proven to be random and not lead to obvious changes in the strain's traits, such as its morphological features, method of working, and effects, the accused product can be judged as constituting infringement under the doctrine of equivalents. The author did not find corresponding infringement cases involving patented genes under the doctrine of equivalents; however, a small number of US cases involving patented proteins had reached the courts on the infringement issue [10]. These cases provided some inspiration for considering the doctrine of equivalents, although the rules are still unclear because of the complexity of biotechnology. On the other hand, if there are highly repetitive regions that cannot be sequenced, important functional genes, regulators, important molecular markers, genes with higher differentiation performance, and ITS rDNA sequences should be considered together for a comprehensive judgment.

Additionally, we should consider situations in which patented strains are used as parents to reproduce or invent new strains. In biotechnology, inventions are evolutionary in nature, as one invention may be created at first, followed by other embodiments in later research phases [11]. DIRECTIVE 98/44/EC OF THE EUROPEAN PARLIAMENT AND OF
THE COUNCIL (July 1998) "on the legal protection of biotechnological inventions" has provided a kind of solution. It stipulates in Article 8 (1) that "The protection conferred by a patent on a biological material possessing specific characteristics as a result of the invention shall extend to any biological material derived from that biological material through propagation or multiplication in an identical or divergent form and possessing those same characteristics." This clause expands the scope of patents of biological materials to the progeny produced by the proliferation of the parent material. The key is whether the biological material has the same characteristics, and there is no restriction on the method by which the biological material can be obtained; "same characteristics" is a flexible expression in the instructions, leaving space for flexible judgment and evidence diversity.

Article 9 of 98/44/EC stipulates that "The protection conferred by a patent on a product containing or consisting of genetic information shall extend to all material, save as provided in Article 5 (1), in which the product is incorporated and in which the genetic information is contained and performs its function." This clause also expands the scope of patents on biological materials. Consider the improved invention of microorganisms as an example. If genetic modification is carried out on the basis of the patented microorganisms to express new functions, but this genetic modification does not interfere with the normal expression of the original microorganism's genes, the newly modified microorganism will still fall into the scope of the original patent.

If the deposit number limited claim of a strain is given such a broad scope of protection, the availability of the deposited strain should be considered at the same time. If the deposited strain has never been furnished and there is no evidence to prove that the strain has been lost illegally or can be obtained by reverse engineering, the judgment should be careful. We cannot exclude the possibility of the coincidence that a third party would obtain the same strain by independent research, especially considering that many wild-type strains are selected from soil or other materials by using conventional methods. In this sense, independent research should be allowed as a defense in action.

\section{Availability of the Deposited Strain}

According to statistics from the WIPO [12], as of the end of 2019 , the total number of deposited patent microorganism was 122,446 . Among them, China's deposits of 33,197, accounting for $27.1 \%$, ranked second in the world. In terms of the annual trend, the number of deposits of China has increased rapidly since 2008. In 2012, it exceeded 2,000 per year, and in 2019, it exceeded 4,000 per year. Therefore, China's deposits in the past nine years (2001-2019) are the highest.

The deposition of microorganisms aims to meet the requirements of publicity and is also proof that the invention has been completed. Publicity implies public access, so according to rule 11.3 of the "Regulations Under the Budapest Treaty on the International Recognition of the Deposit of Microorganisms for 
the Purposes of Patent Procedure", the member states of the treaty are required to "provide samples to those who have legal rights," but there is no rigid stipulation on the time and conditions of furnishing samples. In fact, the number of furnishing deposited samples is quite small. Except for 28,849 in the United States, there are less than 1000 in other countries. For example, Japan, Germany, the United Kingdom, France and China are 902, $877,616,197$, and 7 , respectively.

Due to the following observations, whether the availability of the deposited microorganisms should be restricted to some extent has become a focal point: (1) after obtaining microorganisms samples, the microorganism can be proliferated indefinitely; (2) furnished microorganisms lack a tracking mechanism for further circulation and are uncontrollable, making it difficult to obtain evidence of illegal using; and (3) the scope of protection of microorganism patents is not clear.

In the United States, where there are no restrictions on the furnishing conditions, there were worries in the industry that potential abuse may be inevitable, even though a congressional report asserted that these doubts and concerns had no empirical support [13].

Therefore, in practice, there are very few countries that do not impose any restrictions on the furnishing of strain samples. From Section E of the "Guide to the Deposition of Microorganisms under the Budapest Treaty" (2020) [14], the author sorted the restriction conditions of members, as shown in Table 1. Three time periods are involved in this table.

Table 1. Restrictions on the availability of samples of deposited microorganisms involved in patents.

\begin{tabular}{|c|c|c|c|}
\hline Restriction & Period 1 & Period 2 & Period 3 \\
\hline $\begin{array}{l}\text { An undertaking not to make the } \\
\text { microorganism, or any culture } \\
\text { derived from the } \\
\text { microorganism, available to } \\
\text { any other person }\end{array}$ & $\begin{array}{l}\text { Australia, Austria, Canada, Brunei, Finland, } \\
\text { Belgium, France, Germany, Greece, } \\
\text { Hungary, Iceland, Netherlands, Portugal, } \\
\text { Moldova, Romania, Singapore, Slovakia, } \\
\text { South Africa (face-to-face guarantee), } \\
\text { Spain, Switzerland, United Kingdom, } \\
\text { European Patent Organization (face-to-face } \\
\text { guarantee) }\end{array}$ & $\begin{array}{l}\text { Australia, Austria, Canada, Brunei, } \\
\text { Finland, Belgium, France, Germany, } \\
\text { Greece, Hungary, Iceland, Netherlands, } \\
\text { Portugal, Moldova, Romania, Singapore, } \\
\text { Slovakia, South Africa (face-to-face } \\
\text { guarantee), Spain, Switzerland, United } \\
\text { Kingdom, European Patent Organization } \\
\text { (face-to-face guarantee) }\end{array}$ & $\begin{array}{l}\text { Canada, European Patent } \\
\text { Organization (option A, face-to-face } \\
\text { guarantee) }\end{array}$ \\
\hline $\begin{array}{l}\text { An undertaking not to make the } \\
\text { biological material available to } \\
\text { any other person }\end{array}$ & $\begin{array}{l}\text { China, Italy (only designated experts are } \\
\text { allowed), Norway (face-to-face guarantee), } \\
\text { South Korea, Serbia, Slovenia (face-to-face } \\
\text { guarantee), Japan (request only if a written } \\
\text { warning is received) }\end{array}$ & $\begin{array}{l}\text { China, Norway (face-to-face } \\
\text { guarantee), South Korea, Japan }\end{array}$ & China \\
\hline $\begin{array}{l}\text { An undertaking to use the } \\
\text { biological material for } \\
\text { experimental purpose }\end{array}$ & $\begin{array}{l}\text { China, Italy (only designated experts } \\
\text { allowed), South Korea, Romania, Serbia, } \\
\text { Slovenia (face-to-face guarantee), Spain, } \\
\text { Switzerland, Japan (request only if a } \\
\text { written warning is received) }\end{array}$ & $\begin{array}{l}\text { South Korea, Romania, Slovenia } \\
\text { (face-to-face guarantee), Spain, } \\
\text { Switzerland, Japan }\end{array}$ & \\
\hline $\begin{array}{l}\text { An undertaking not to use a } \\
\text { sample of the deposited } \\
\text { biological material or a } \\
\text { material derived therefrom for } \\
\text { anything else but experimental } \\
\text { purposes }\end{array}$ & $\begin{array}{l}\text { Austria, France, Finland, Germany, Greece, } \\
\text { Hungary, Iceland, Netherlands, Portugal, } \\
\text { Moldova, Slovakia, European Patent } \\
\text { Organization (face-to-face guarantee) }\end{array}$ & $\begin{array}{l}\text { Austria, Finland, Germany, Greece, } \\
\text { Hungary, Netherlands, Portugal, } \\
\text { Moldova, Slovakia, European Patent } \\
\text { Organization (face-to-face guarantee) }\end{array}$ & \\
\hline $\begin{array}{l}\text { An undertaking to use the } \\
\text { sample of biological material } \\
\text { and any culture derived from } \\
\text { such a sample only for the } \\
\text { purpose of experiments that } \\
\text { relate to the subjectmatter of } \\
\text { the application }\end{array}$ & $\begin{array}{l}\text { Canada, BruneiDarussalam, Singapore, } \\
\text { United Kingdom, Norway (guarantee in } \\
\text { person) }\end{array}$ & $\begin{array}{l}\text { United Kingdom, Norway (guarantee in } \\
\text { person) }\end{array}$ & Canada \\
\hline $\begin{array}{l}\text { To use the microorganism only } \\
\text { for experimental purposes, in } \\
\text { relation to the opposition } \\
\text { proceedings }\end{array}$ & Australia & Australia & \\
\hline $\begin{array}{l}\text { Only be available to a special } \\
\text { expert }\end{array}$ & $\begin{array}{l}\text { Patent applicants have the right to request: } \\
\text { Finland, Belgium, Czech Republic, } \\
\text { Germany, Greece, Iceland, Netherlands, } \\
\text { Norway, Portugal }\end{array}$ & $\begin{array}{l}\text { The patentee has the right to request: } \\
\text { Czech Republic, Iceland }\end{array}$ & $\begin{array}{l}\text { Patent applicants have the right to } \\
\text { request: Czech Republic, Iceland. } \\
\text { If the application has been refused or } \\
\text { withdrawn or deemed to be } \\
\text { withdrawn, patent applicants have } \\
\text { the right to request: Finland, } \\
\text { Belgium, Greece, Portugal, Moldova, } \\
\text { Romania, Slovakia, Spain, European } \\
\text { Patent Organization (Option B) }\end{array}$ \\
\hline No guarantee required & & United States, Serbia & $\begin{array}{l}\text { Australia, Austria, France, Hungary, } \\
\text { South Africa, United Kingdom }\end{array}$ \\
\hline
\end{tabular}

Period 1: The patent application has been published and is

pending; 
Period 2: The patent has been authorized and is still valid;

Period 3: The patent application is not authorized, or the authorized patent has expired, but it is still within the preservation period.

As shown in Table 1, the restrictions on sample furnishing in different countries are quite different in different time periods. In terms of "not providing the material to a third person", stricter restrictions extend to derived materials. In terms of "experimental purposes only", stricter restrictions limit the purposes where the sample can only be used for patent-related procedures such as opposition procedures, or it can only be used for experimental purposes related to the subject of the application. Even the improved experiment based on the material itself is not allowed. Some countries allow the "independent expert" option, that is, the sample is only used for experimental purposes by independent experts.

The author agrees with that if there are no restrictions on strain sample furnishing, the abuse of strains may be widespread. It is necessary to restrict furnishing strain samples to some extent. In fact, in the material transfer agreement (MTA), some restrictive clauses are more stringent [15]. However, from the perspective of promoting scientific and technological innovation, there should be a certain boundary for this kind of restriction. Otherwise, it will severely limit the improvement of research and development on the basis of existing technology and will be contrary to the legislative purpose of the Patent Law. To determine whether such improved research and development results fall into the scope of protection of the original patent, the principle of infringement should be clarified as above from the perspective of promoting innovation and the balance of interests.

\section{Conclusion}

For a case involving a deposit number limited claim of strains, the first task is to clarify the scope of protection of the claims. The deposit number limited claim of a strain can be interpreted as "a strain that has the same specific characteristics as the strain deposited in qualified depository institution," which retains flexibility for judgment. Although there are some specific questions, no specific doctrine is required to resolve the infringement issues that arise in such cases. Both literal infringement and infringement under the doctrine of equivalents can be applied to deal with problems, as in the case of protein patents. When the full genomic is available, the genomic sequences should be compared in action; only in some specific conditions in which full genomic sequencing is difficult to obtain, other molecular markers can be considered. In addition, particular care is required when considering infringement under the doctrine of equivalents, especially when recombinant DNA technology is used to change the strain.

The deposited strain should be available for public. Considering the possibility of strains being abused, certain restrictions could be allowed in furnishing deposited strains.
However, it is inappropriate to refuse to furnish strains simply because it is difficult to trace them. Those stricter restrictions are unbalanced, such as the requirement to "use the deposited biological material sample or its derivative material only for an experimental purpose related to the subject of the application" or "only for a patent-related experimental purpose". Patent protection and trade secret protection should not coexist.

\section{References}

[1] Eisenberg, R. S. Proprietary rights and the norms of science in biotechnology research [J]. Yale Law Journal, 1987, 97 (2): 177-231.

[2] United States v. Bottone, 365 F. 2d 389 (1966).

[3] Diamond v. Charkrabarty, 447 U.S. 303 (1980).

[4] Shanghai FINC v. Tianjin LSPY, (2017) Beijing 73 civil preliminary case No. 555, China. https://wenshu.court.gov.cn/website/wenshu/181107ANFZ0B XSK4/index.html?docId $=61$ cea31a2c5a46bc8a4daca1000c6c4 f, last visited Jan. 22, 2021.

[5] Anna-Ida Johnsson Holmberg, PetterMelin, Jens P. Levenfors, Ingvar Sundh. Development and evaluation of SCAR markers for a Pseudomonas brassicacearum strain used in biological control of snow mould [J]. Biological Control, 2009, 48 (2): 181-187.

[6] WX31871, Judgment of Reexamination and Invalidation Department of the Chinese National Intellectual Property Administration.

http://reexam-app.cnipa.gov.cn/reexam_out2020New/searchd oc/decidedetail.jsp?jdh=31871\&lx=wx, last visited Jan. 22, 2021.

[7] Schoch CL, Seifert KA, Huhndorf S, et al. Nuclear ribosomal internal transcribed spacer (ITS) region as a universal DNA barcode marker for Fungi [J]. Proceedings of the National Academy of Sciences of the United States of America, 2012, 109 (16): 6241-6246.

[8] Organism name: Hypsizygusmarmoreus (basidiomycetes). ASM160531v2. [GenBank] IDs: 1834041 [UID] 6946218, Date: 2018/07/25, https://www.ncbi.nlm.nih.gov/assembly/GCA_001605315.2/, last visited Jan. 22, 2021.

[9] He Peixin. Advanced Microbiology. China Light Industry Press, first edition in August 2017: 298.

[10] Gregory B. Sephton. Biotechnology: The Doctrine of Equivalents and Infringement of Patented Proteins [J]. Suffolk University Law Review. 1991, 25 (4): 1035 -1070.

[11] Harold C. Wegner. Equitable Equivalents: Weighing the Equities to Determine Patent Infringement in Biotechnology and Other Emerging Technologies [J]. Rutgers Computer \& Technology Law Journal, 1992, 18 (1): 1-50.

[12] Microorganisms Deposits and Samples (2001 - 2019), Source: WIPO Statistics Database (August 2020), https://www.wipo.int/treaties/zh/registration/budapest/, last visited Jan. 22, 2021. 
[13] U.S. General Accounting Office. Report to Congressional Committees GAO-01-49, Intellectual Property: Deposits of Biological Materials in Support of Certain Patent Applications (Oct. 2000), www.gao.gov/new.items/d0149.pdf, last visitedJan. 22, 2021.

[14] Section E: Requirements of Industrial Property Offices of States Party to the Budapest Treaty and of intergovernmental Industrial https://www.wipo.int/export/sites/www/treaties/en/registration /budapest/guide/pdf/section_e.pdf, last visitedJan. 22, 2021.

[15] Streitz W D, Bennett A B. Material transfer agreements: a university perspective [J]. Plant Physiology, 2003, 133 (1): 10-13. 